\title{
Kuzey Marmara Otoyolunda dere köprüsü tasarımı ve uygulaması: Alemdağ dere köprüsü örneği
}

\author{
Fatih Süleyman DENIZOLGUN', Yavuz Selim GÜÇLÜ ${ }^{2, *}$, Zekai ŞEN $^{3}$ \\ ${ }^{l}$ İstanbul Teknik Üniversitesi, İnşaat Müh. Bölümü, Hidrolik Lab., Maslak, İstanbul, Türkiye \\ ${ }^{2}$ İstanbul Medeniyet Üniversitesi, Inșaat Müh. Bölümü, Ünalan-Üsküdar, İstanbul, Türkiye \\ ${ }^{3}$ İstanbul Medipol Üniversitesi, İnşaat Müh. Bölümü, Beykoz, İstanbul, Türkiye
}

Gelis Tarihi (Recived Date): 04.03.2018

Kabul Tarihi (Accepted Date): 18.06.2018

\section{Özet}

Bu çalışma Yavuz Sultan Selim Köprüsü’ne bağlantıyı sağlayan Kuzey Marmara Otoyolu'nun Ümraniye Alemdă dere köprüsüne ait hidrolojik, hidrolik ve boyutlandırma hesaplarını içermektedir. Bu çalışmada kullanılan veriler Meteoroloji Genel Müdürlüğ̈̈ (MGM)'nden alınmıştır. İstanbul'un $33 \mathrm{~m}$ rakımlı Göztepe yağış istasyonunda yapılmış ölçümler 1942-2007 arasında 66 yılın en yüksek yağışları olarak seçilmiştir. Ǘç ana adımdan müteşekkil bu uygulama çalışması için ilk aşamada yağış verilerinin trend (ĕ̌ilim) analizleri gerçekleştirilmiştir. Bunun için Şen yöntemi ve Mann-Kendall sınaması ile trend analizi çalışması ortaya koyulmuştur. Elde edilen analiz sonuçlarına göre ikinci ana adımda olasılık ve yığışımlı (kümülatif) dă̆llım fonksiyonları kullanılarak ilgili grafikler ve sayısal sonuçlar hesaplanmıştır. Üçüncü ana adımda tasarım debisi hesaplama kısmına geçilerek ilgili havzada belli tekerrür aralı̆̆ında dïşecek yağış değerine göre toplanacak debi belirlenmiştir. Tasarım debisi hesaplama yöntemleri Snyder yapay birim hidrograf yaklaşımı ve DSİ yöntemi kendisinde barındırdıkları tepe (pik) debi ile bu çalışma için yeterli olmuştur. Kanalın debi kapasitesinin hesaplaması ise klasik Manning denklemi ile yapılmıştır.

Anahtar kelimeler: Kuzey Marmara Otoyolu, Snyder yapay birim hidrograf, DSI yöntemi, Trend, Yavuz Sultan Selim Köprüsü.

Fatih Süleyman DENIZOLGUN, fatihsuleyman@gmail.com

*Yavuz Selim GÜÇLÜ, yavuzselim.guclu@medeniyet.edu.tr, https://orcid.org/0000-0002-9939-1157

Zekai ŞEN, zsen@medipol.edu.tr 


\title{
Design and implementation of stream bridge in Northern Marmara Highway: Alemdag stream bridge
}

\begin{abstract}
This study includes hydrologic, hydraulic and sizing calculations of Umraniye Alemdag Stream Bridge of Northern Marmara Highway that leads to Yavuz Sultan Selim Bridge. In this paper, the data are provided from General Directorate of Meteorology. Measurements cover the period of 66 years between 1942 and 2007. They are recorded in Istanbul Goztepe rainfall station that has 33 meters altitude from the mean sea level. Thus, consequences are calculated by analyses, forecasts and calculation for 66 extreme rainfall measurements. In the first part, rainfall data trend analysis has been obtained with Şen's approach and Mann-Kendall test. According to analysis results, the graphics are drawn and mathematical results are calculated by weibull cumulative distribution functions and probability distribution functions in the second main step. The third main step calculations are performed for design discharge. Discharge is determined according to rainfall frequencies in the basin. On the other hand, discharge capacity has been calculated by designing stream bridge that has highway on top of it. Snyder and DSI synthetic unit hydrograph approaches are sufficient for computations of the peak discharge in this study. The calculation step of the discharge capacity of the channel is obtained with the Manning equation.
\end{abstract}

Keywords: Northern Marmara Highway, Snyder synthetic unit hydrograph, DSI method, Trend, Yavuz, Sultan Selim Bridge.

\section{Giriş}

Dünyada en sık görülen doğal afet çeşitlerine bakıldığında su ile ilişkilendirilenler göze çarpmaktadır [1]. Su miktarının doğal veya yapay yataklarının taşıma kapasitesini aşması sonucunda meydana gelen taşkınlar, seller ve su basmaları Türkiye'de de en sık görülen ama maddi zarar ve can kaybı açısından depremden sonra en etkili afetlerdir. Şehirleşmenin yoğunlaştığı yerlerde taşkınların meydana geliş nedenlerine odaklanıldığında daha çok ulaşım ağı sebebiyle sorunların ortaya çıktığı görülmektedir. Özellikle, menfez ve dere köprülerinin bulunduğu noktalar en kritik yerlerdir ve uygun boyutlandırma yapılmamışsa bu noktalar adeta baraj gibi çalışarak suyun menbaaya doğru şişmesine sebep olmaktadırlar. Mesela, 2009 yılında İstanbul Ayamama havzasında ortaya çıkan taşkın, üzerinden karayolu geçen bir kesitten (dere köprüsü) suyun tam anlamıyla geçememesi sebebiyle meydana gelmiştir.

Günümüzün en güncel konularından biri de küresel 1sınmanın ortaya çıkardığı iklim değişikliğidir. Bilhassa, taşkın ve kuraklık gibi afet durumlarının uç değerlerinde artışlar meydana gelmektedir. Dolayısıyla, su mühendislerinin bu iklim değişikliği meselesini eğilim (trend, gidiş, genel temayül) çözümlemesi (analizi) kapsamında dikkate alarak plan ve projelerini geliştirmeleri gerekmektedir [1].

Açık kanal (yapay veya doğal), köprü ve menfez tasarımları için 18. Yüzyılın ortalarından beri taşkın olaylarına dayalı bir takım amprik (tecrübeye dayanan) denklemler ortaya koyulmuştur. Henüz yağış ölçümü olmadığı zamanlarda araştırmacı 
O'Connell [2] taşkın tahmin, diğer bir deyişle hidroloji hesap konusundaki ilk çalışmayı sunmuştur. Diğer taraftan, 1880'de İsviçreli mühendis Burkli-Ziegler tarafından önerilen başka bir denklem ilk olarak 1911 yılında yayınlanmıştır [3]. İlk aşamada ünlü olmayan ve diğer yöntemlere nazaran az kullanılan akılcı (rasyonel) yöntem [4] ise özellikle küçük havzalar için oldukça yoğun kullanım alanı bulmuştur.

Belli bire süre yağan birim yükseklikteki artık yağışın ortaya çıkaracağ 1 hidrografa birim hidrograf $(\mathrm{BH})$ adı verilmektedir. Sherman [5] tarafından geliştirilen $\mathrm{BH}$ modeli sadece en büyük (maksimum) debiyi belirlemenin yanında zamanla debinin değişimini içerecek şekilde son derece açıklayıcı bir grafik önermiştir. Yağış-akış ölçümleri bulunmayan havzalarda kullanılması mümkün olmayan $\mathrm{BH}$ için sentetik olanlara başvurulmak zorundadır. Bunun için 1938 yılında ilk defa Snyder [6] isimli araştırmacı tarafından havzanın yüzey şekilleri fiziki yapısına bakılarak sentetik BH üretilmiş ve günümüzde de yoğun bir şekilde kullanılmaktadır. Yukarıda bahsedilen yöntemlerin uygulamalarına dair daha ayrıntılı bilgileri Chow [7]'un eserinden edinmek mümkündür.

DSİ yöntemi Türkiye'de oldukça yaygın kullanıma sahip sentetik yöntemlerden biridir. Birçok araştırmacı DSİ yöntemini diğer yöntemlerle karşılaştırmalı bir şekilde dikkate alarak çalışmalarını sunmuşlardır. Eren [8] ortaya çıkardığı tez çalışmasında İstanbul Silivri ilçesindeki Boğluca deresi için beş farklı debi tahmin yöntemini (DSİ, Mockus, SCS, Synder Birim Hidrograf, Rasyonel Metot) kıyaslayarak taşkın debilerini hesaplamıştır. Benzer şekilde Günal [9] pik debi ve pik debinin ortaya çıkış süresi gibi parametreleri Snyder, Mockus, SCS ve DSİ metotlarını kullanarak hesaplamıştır. İlgili uygulamalar ve karşılaştırmalar Türkiye'nin Damlıca, Vize ve Kumdere havzaları için gerçekleştirilmiştir. DSİ yöntemine dair ortaya koyulan diğer bir çalışma [10] ise Kırıkkale il sınırları içinde bulunan Çoruhözü deresi havzası için gerçekleştirilmiştir. İşler vd. [11] sundukları çalışmada havza karakteristiklerini Coğrafi Bilgi Sistemlerini de kullanarak hesaplarken taşkın debilerini Mockus yöntemi, DSİ yaklaşımı ve SCS yağış-akış modeli ile tahmin etmeye çalışmışlardır.

$\mathrm{Bu}$ uygulama çalışmasında tasarım debisini belirlemek için Snyder ve DSİ sentetik birim hidrograf yöntemine başvurulacaktır çünkü ilgili havzanın mecrası kuru dere özelliğindedir ve her hangi bir akış ölçümü yapılmamıştır.

Bir havzada tasarım debisi belirlendikten sonra çıkış noktasında bulunan en kesitten bu debinin geçip geçmeyeceğine dair kanal kapasite hesabı (hidrolik hesap) yapılmalıdır. Manning [12] tarafından geliştirilen denklem sayesinde doğal veya yapay en kesitler için hidrolik hesaplar yapılabilmektedir. Ponce [13] isimli araştırmacı ortaya koyduğu eserde açık kanallara dair tüm ayrıntılarıyla açıklamalarda bulunmuştur ve Manning denklemi ile ilgili çok daha ayrıntılı bilgiye bu eserden ulaşılabilmektedir. $\mathrm{Bu}$ çalışmada Manning bağıntısı kullanılarak ilgili en kesitin debi taşıma kapasitesi hesaplanacaktır.

İklim değişikliği zamanla daha da hissedilmeye başlamıştır, çünkü dünyayı adeta bir battaniye gibi saran sera gazlarında gün geçtikçe sürekli bir artış vardır. Bunun sonucunda küresel 1sınma başta hidro-meteorolojik olaylara olmak üzere bir takım etkiler yapmaya başlamıştır. Diğer bir ifadeyle, dünyanın farklı yerlerinde yapılan hidrolojik ve meteorolojik ölçümlerin bazılarında artış bazılarında da azalışlar görülmektedir. Bahsi geçen azalış veya artışları belirlemek adına araştırmacılar eğilim 
analiz yöntemleri önermişlerdir [14-17]. Son zamanlarda önerilen şekilsel (grafiksel) eğilim analiz yaklaşımı 1:1 doğru $\left(45^{\circ}\right)$ yöntemi her türlü zaman dizisine uygulanabilmektedir [18]. Bu çalışmada yağıș şiddetlerinin eğilim durumu da Şen [18] ve Mann-Kendall [14-15] yöntemlerine göre bakılıp bir artış (güvenlik) katsayısının kullanılıp kullanılmayacağına karar verilecektir.

$\mathrm{Bu}$ çalışmanın hedefi, açılışı son zamanlarda gerçekleştirilen Yavuz Sultan Selim Köprüsü' ne bağlantıyı sağlayan Kuzey Marmara Otoyolu'nun Ümraniye Alemdağ dere köprüsüne ait hidrolojik, hidrolik ve boyutlandırma hesaplarını gerçekleştirmektir. Burada, tasarım debisinin ve hidrolik hesapların kullanılacağı yöntemler, olasılık hesapları, ilgili trend analiz yöntemleri aktarılacaktır ve yöntemlerin gerektirdiği adımlar atılarak uygulama gerçekleştirilecektir.

\section{Yöntem}

Üç aşamalı bu çalışmanın ilk aşamasında yağış verilerinin eğilimlerine bakılmıştır. Bunun için Şen ve Mann-Kendall yöntemleri ile eğilim analizi çalışması ortaya koyulacaktır. Elde edilen analiz sonuçlarına göre ikinci adımda olasılık ve yığışımlı dağılım fonksiyonları (ODF ve YDF) kullanılarak ilgili grafikler çizdirilecek ve sayısal sonuçlar hesaplanacaktır. Üçüncü adımda ise tasarım debisi hesaplama kısmına geçilerek ilgili havzada belli tekerrür aralığında düşecek yağışa göre akışa geçecek debi belirlenecektir. Havzanın çıkış noktasında üzerinden karayolu geçen dere köprüsü tasarlanarak en kesitten geçebilecek debi kapasitesi bulunacak ve gerekli kıyaslamalar gerçekleştirilecektir.

\section{1. Ĕgilim analizi: Şen yöntemi ve Mann-Kendall sınaması}

$\mathrm{Bu}$ analiz için yukarıda da ismi verilen bazı yöntemler ortaya atılmıştır. Birçok araştırmacı [19-24] tarafından uygulaması yapılan 1:1 doğru $\left(45^{\circ}\right)$ yöntemi (Şekil 1) bu çalışmada trendi belirlemek için kullanılmıştır. Bu basit yöntemin uygulama adımlarını şu şekilde sıralamak mümkündür. Öncelikle elde edilen herhangi bir veri dizisi zamansal olarak önceki ve sonraki yarım olmak üzere iki eşit uzunluklu diziye ayrılır. İkinci olarak da, her bir yarım veri dizisi küçükten büyüğe veya büyükten küçüğe siralanır. Sonra Kartezyen koordinat sisteminde yatay eksene önceki yarımın verileri, düşey eksene de sonraki yarım verileri koyularak saçılma diyagramı elde edilir. Son olarak, saçılan verilerin 1:1 doğruya göre konumuna bakarak zaman dizisinde eğilim varlığına, eğilim varsa yapısına karar verilir. Şekil 1'de ayrıca zaman dizilerinde gerçekleşebilecek tüm eğilim durumları gösterilmiştir. 


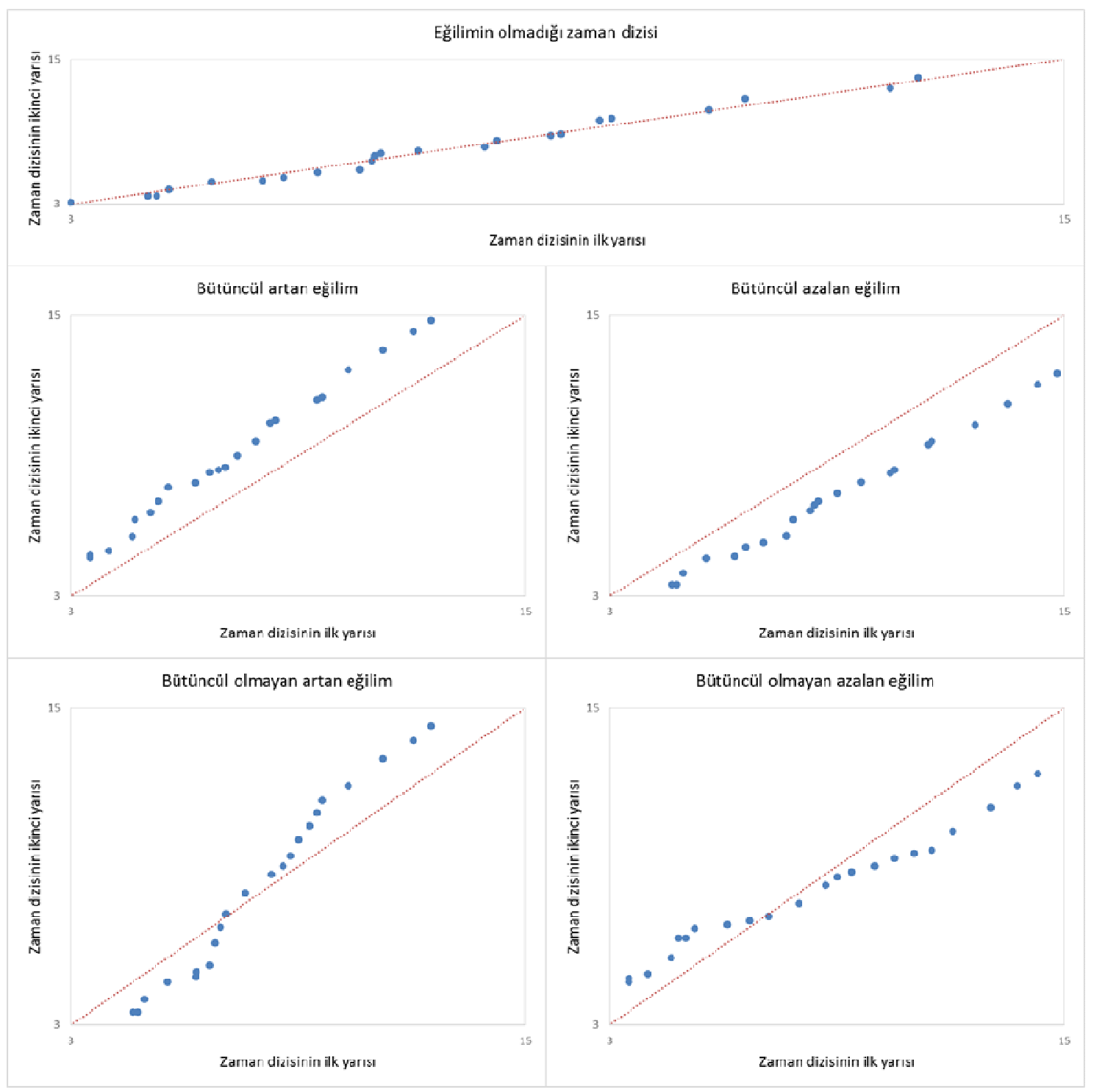

Şekil 1. 1:1 Doğrusu üzerinde eğilim (trend) durumları [18].

Diğer bir yöntem Mann-Kendall sınamasında ise artan veya azalan trend kararı $\mathrm{Z}$ (Denklem 1) değerine göre verilmektedir. Eğer Z eksi bir değer hesaplanmış ise ilgili zaman dizisi azalandır, artı ise artandır denilmektedir. Ancak, seçilen $\alpha$ anlamlılık seviyesine $\quad(\alpha=20 \% \quad(\mathrm{Z} \geq \mathrm{Z} \alpha / 2=| \pm 1.28|), \quad \alpha=10 \% \quad(\mathrm{Z} \geq \mathrm{Z} \alpha / 2=| \pm 1.645|), \quad \alpha=5 \%$ $(\mathrm{Z} \geq \mathrm{Z} \alpha / 2=| \pm 1.96|)$ veya $\alpha=2 \%(\mathrm{Z} \geq \mathrm{Z} \alpha / 2=| \pm 2.33|))$ göre trendin varlığ kabul edilir veya reddedilir. Denklem 1 'de istenen $\mathrm{V}(\mathrm{S})$, varyans ve $S$, Mann-Kendall istatistiği, takip eden diğer denklemlerde sırasıyla verilmiştir.

$$
z= \begin{cases}S-1 / \sqrt{V(S)} & \text { for } S>0 \\ 0 & \text { for } S=0 \\ S+1 / \sqrt{V(S)} & \text { for } S<0\end{cases}
$$




$$
\begin{aligned}
& V(S)=\frac{n(n-1)(2 n+5)}{18} \\
& S=\sum_{k=1}^{n-1} \sum_{j=k+1}^{n} \operatorname{sgn}\left(x_{j}-x_{k}\right) \\
& \operatorname{sgn}\left(x_{j}-x_{k}\right)=\left\{\begin{array}{lll}
+1 & \text { if } & \left(x_{j}-x_{k}\right)>0 \\
0 & \text { if } & \left(x_{j}-x_{k}\right)=0 \\
-1 & \text { if } & \left(x_{j}-x_{k}\right)<0
\end{array}\right.
\end{aligned}
$$

\subsection{Olasilık hesaplamalart}

İhtimal hesaplamaları için ilk aşamada uzun süreli ölçümlerin elde edilmesi gerekmektedir. Ölçülmüş verilerle öncelikle histogramlar elde edilir ve bu histogramlara uygun olasılık veya yığışımlı olasılık dağılım fonksiyonları (ODF ve YDF) ayarlanır. $\mathrm{Bu}$ aşamadan sonra seçilen sıklık esas alınarak şiddet değerleri belirlenir. Mesela, n yıllık frekans (sıklık) için $\mathrm{F}=1 / \mathrm{n}$ denklemi kullanılarak ODF'nun sağ kuyruğu veya YDF üzerinde 1-1/n'ye karşılık gelen sonuç göz önünde tutularak yağış şiddeti değerleri elde edilir (Şekil 2) [24].
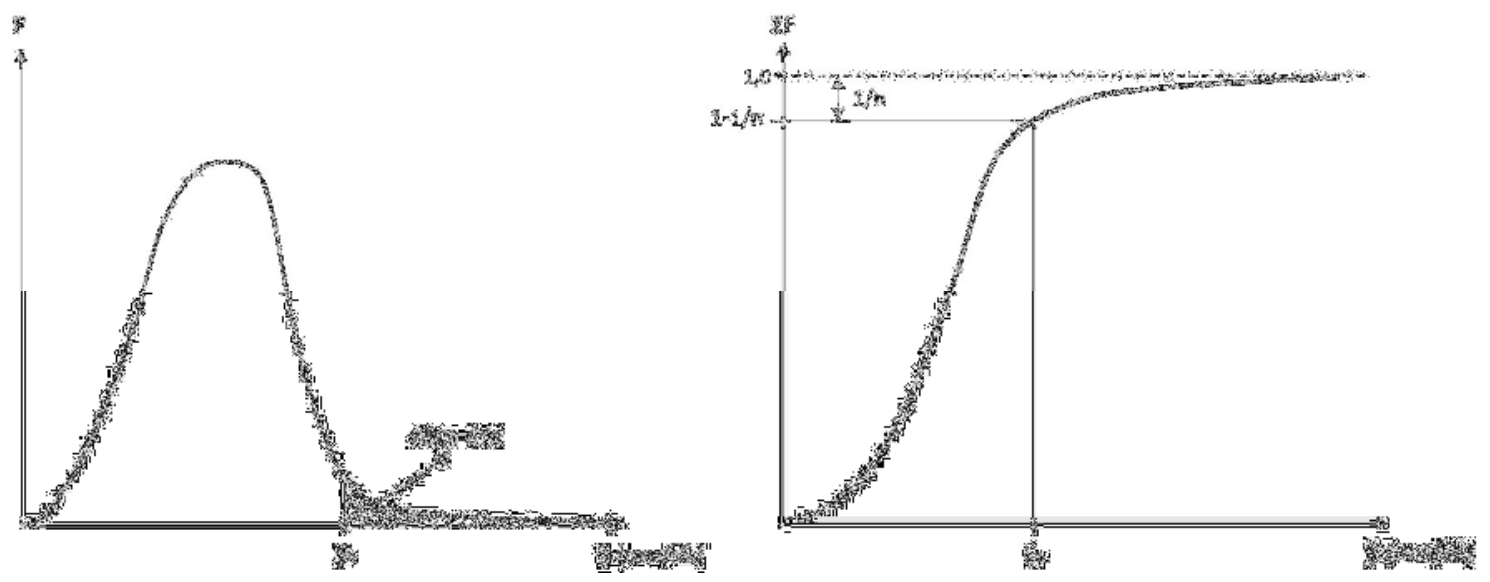

Şekil 2. Örnek ODF ve YDF ile n yıllık sıklığa sahip yağış şiddeti (Ş) değerinin hesaplanmasi.

ODF ve YDF'ları için onlarca denklem çeşidi bulunmaktadır. Bu çalışmada; LogPearson-3, 2 ve 3 parametreli Weibull, Gamma, Lognormal, 2 parametreli Gumbel, Normal, Üstel ve Genelleştirilmiş Ekstrem Değer dağılımları kullanılacaktır. Kolmogorov Simirnov [25, 26], Anderson Darling [27, 28] ve Ki-Kare [29] sinama sonuçlarına göre de kullanılacak dağılım fonksiyonuna karar verilecektir.

\subsection{Snyder sentetik brim hidrograf yaklaşımı, DSİ yöntemi ve Manning denklemi}

Tasarım debisi hesaplama yöntemi olan Snyder yapay birim hidrograf yaklaşımı ve DSİ yöntemi kendilerinde barındırdığı tepe (pik) $\left(Q_{p}\right)$ debi ile bu çalışma için yeterli olacaktır. Havza özelliklerinden faydalanarak elde edilen bu birim hidrografların gerçek hidrografa çevrilebilmesi için bir yağış değerine ve bu değerden de artık yağış 
ifadesine gerek duyulmaktadır. Artık yağıș hesaplama adına ASCE [30] zemin ve havza kullanım özelliklerine göre akıș katsayılarını ayrıntılı bir şekilde vermiştir.

Snyder yöntemini yöneten bir takım katsayılar ve denklemler mevcuttur, fakat bir havza için yağış-akış verileri ölçülmüşse, bazı ayarlamalarla (kalibrasyonlarla) hidrograf çizdirilebilmektedir. Bu çalışmanın uygulamasında kullanılan havzada bu tür veriler bulunmadığından fiziksel özelliklerden faydalanılacaktır.

Bir havzanın zemin, eğim, kullanım maksadı gibi özellikleri bilindikten sonra Snyder hidrografını ortaya çıkaran iki katsayı mevcuttur. Pik debinin belirlenmesine yarayan ve boyutsuz katsayı $\mathrm{C}_{\mathrm{p}}$ ' dir. Bu katsayının değişim aralığı genellikle 0.22-2.45'tir. Diğer bir katsayı olan $C_{t}$ pik debinin yağış başladıktan ne kadar süre sonra gözükeceğini ifade etmektedir. Sonuç olarak, $C_{t}$ ve $C_{p}$ belirlendikten sonra hesaplamalar aşağıdaki iki ana denklem vasitasiyla hidrograf elde edilebilecektir.

$$
\begin{aligned}
& t_{p}=0.75 C_{t}\left(L L_{c}\right)^{0.3} \\
& Q_{p}=\frac{2.78 A C_{p}}{t_{p}}
\end{aligned}
$$

$t_{p}$ (saat) hidrografta uç debinin ortaya çıkması için geçen süre, $L(k m)$ kanal uzunluğu, $\mathrm{L}_{\mathrm{c}}(\mathrm{km})$ havza merkezinin esas mecra üzerindeki izdüşümünün çıkış noktasına kuş uçuşu uzaklığıdır, A $\left(\mathrm{km}^{2}\right)$ ise havza alanıdır.

Bu makalede dikkate alınacak diğer debi tahmin yöntemi DSİ yaklaşımıdır. Bir mm yükseklikteki yağışın bir $\mathrm{km}^{2}$ alanda ortaya çıkaracağı birim debi, $\mathrm{q}_{\mathrm{p}}$, hesaplanırken denkleme (Denklem 6) ayrıca harmonik eğim, S, değeri dâhil edilecektir. Harmonik eğim Denklem 7 ile elde edilebilen bir değerdir. Birim hidrografa ait tepe debi, $\mathrm{Q}_{\mathrm{p}}$, değerine ise Denklem 8 sayesinde ulaşmak mümkündür.

$$
q_{p}=\frac{414}{A^{0.225}\left(\frac{L L_{c}}{\sqrt{s}}\right)^{0.16}}
$$

$$
S=\left(\frac{10}{\sum \frac{1}{\sqrt{\Delta H / \Delta L}}}\right)^{2}
$$

$$
Q_{p}=A q_{p} 10^{-3}
$$

Hidrograf su kaynakları yönetimi, baraj tasarımı, taşkın tahmini ve taşkın haritası gibi konular için büyük önem arz etmektedir. Ancak bu çalışmada sadece ilgili kanalın debi taşıma kapasitesinin belirleme çalışması yapılacağından sadece pik debi değeri dikkate alınacaktır. 
Kanalın debi kapasitesinin hesaplama adımı klasik Manning denklemi (Denklem 9) ile atılacaktır. Bu denklemde $\mathrm{R}$ hidrolik yarıçap ve $\mathrm{S}$ kanal eğimidir. Manning katsayısı (n) ise Tablo 1'e göre belirlenecektir.

$V=(1 / n) R^{2 / 3} S^{1 / 2}$

Tablo 1. n katsayısının kanal özelliğine göre değerleri.

\begin{tabular}{cc}
\hline \hline Kanal Malzemesi & n Değeri \\
\hline Asfalt & $0.016-0.020$ \\
Beton-Pürüzsüz & $0.011-0.016$ \\
Beton-Pürüzlü & $0.012-0.020$ \\
Toprak-Pürüzsüz & $0.018-0.023$ \\
Toprak-Pürüzlü & $0.022-0.035$ \\
Doğal-Temiz & $0.030-0.040$ \\
Doğal-Engebeli & $0.035-0.075$ \\
\hline
\end{tabular}

Ponce [13] isimli araştırmacı ortaya koyduğu eserde açık kanallara dair ayrıntılı açıklamalarda bulunmuştur ve Manning denklemi ile ilgili detaylı bilgiye bu eserden ulaşılabilmektedir.

\section{Uygulama}

İstanbul 15 milyon civarındaki nüfusuyla dünyanın en kalabalık şehirleri arasında gelir. Mevcut hizmetler yetersiz kaldığı için en önemli sorunlarından biri kent içi ulaşımın düzene sokulması meselesidir. Bu kapsamda iki kıtayı birleștiren 15 Temmuz Şehitler (Boğaziçi) ve Fatih Sultan Mehmet köprülerine ek olarak boğazın altından Marmaray ve Avrasya Tüneli ile boğazın üstünden de Yavuz Sultan Selim Köprüsü inşa edilip devreye sokulmuştur. İstanbul boğazının kuzeyinde konumlanan köprü, Avrupa Yakası'nda Sarıyer'in Garipçe mahallesi ile Anadolu Yakasında Beykoz'un Poyrazköy semtinde yer almaktadır. Bu köprü için bağımsız bir güzergâh seçildiği için tüm ana ve bağlantı yolları sıfırdan tasarlanıp inşa edilmiştir. İstanbul'un kuzeyinde meydana getirilen bu ağın adı Kuzey Marmara Otoyolu (KMO) olarak belirlenmiştir (Şekil 3).

İstanbul'un kuzey kesimleri doğal havzalar iken yeni örülen ulaşım ağı sebebiyle bir takım yapaylıklar içermeye başlamıştır. Daha da önemlisi yağışın olmadığı dönemde kuru iken yağışlı sürelerde ıslak dereler; kara ve demiryolları ile kesilmiştir. Küçük parçalarda toplanacak akışın bu tarz yerlerden geçişi için menfez türü sanat yapılarıyla üstesinden gelirken, onlarca kilometre karelik havzalardan gelecek akışı geçirmesi için dere köprüleri tasarlanıp inşa edilmektedir. Kuzey Marmara Otoyolu'nun hem Avrupa hem de Asya yakasında çok sayıdaki menfezin yanında dere köprüleri de mevcuttur. Bu çalışmada, Asya tarafında bulunan dere köprülerinden Ümraniye Alemdağ Dere Köprüsü (DK02) çalışma alanı olarak belirlenmiştir (Şekil 3). İlgili havzada debi hesab1 için kullanılacak yağış verileri Meteoroloji Genel Müdürlüğüne (MGM) ait üç farklı yağış istasyonu ile ilişkilendirilebilmektedir (Şekil 4 ve Tablo 2). 


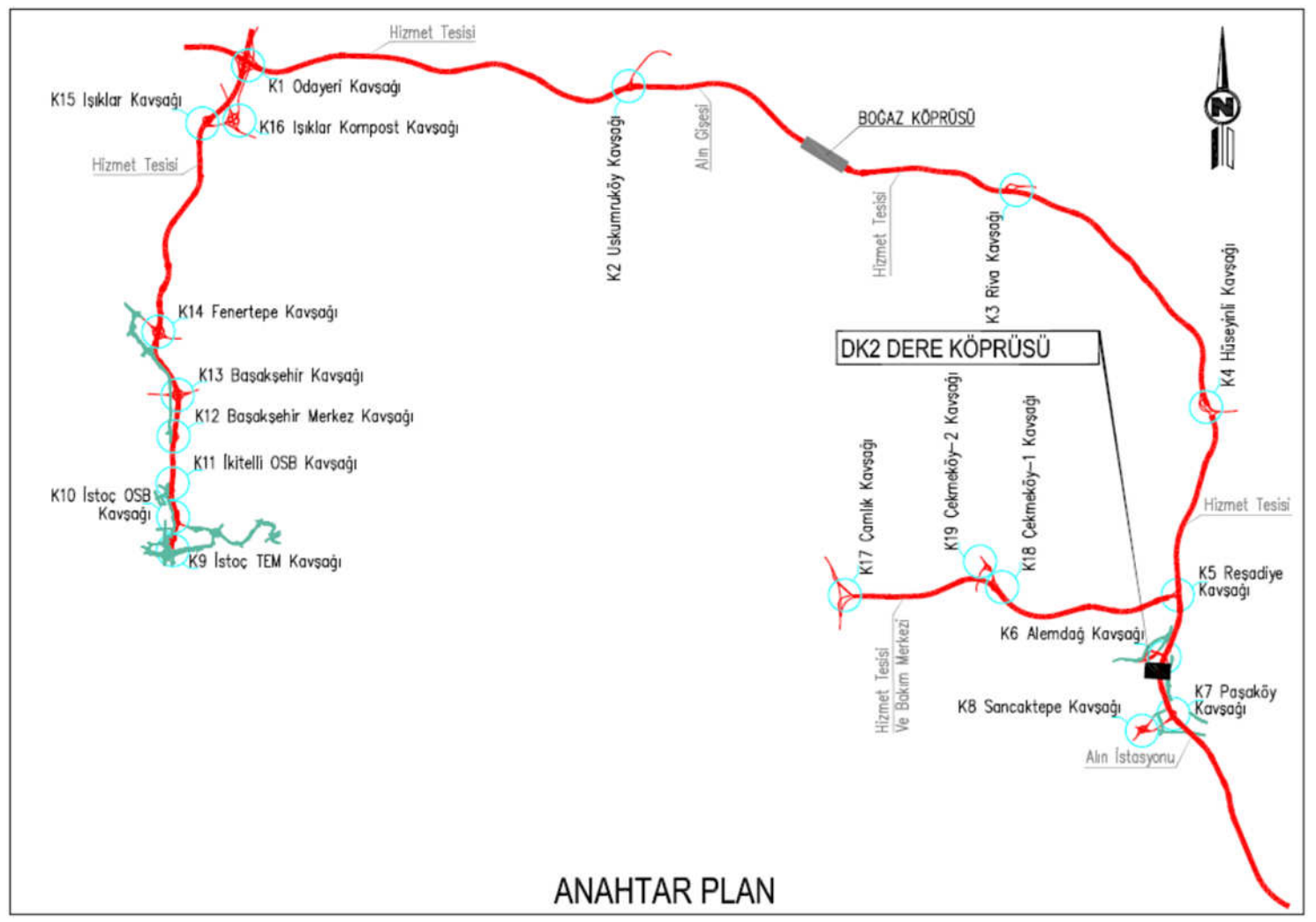

Şekil 3. KMO anahtar planı ve DK02'nin konumu.

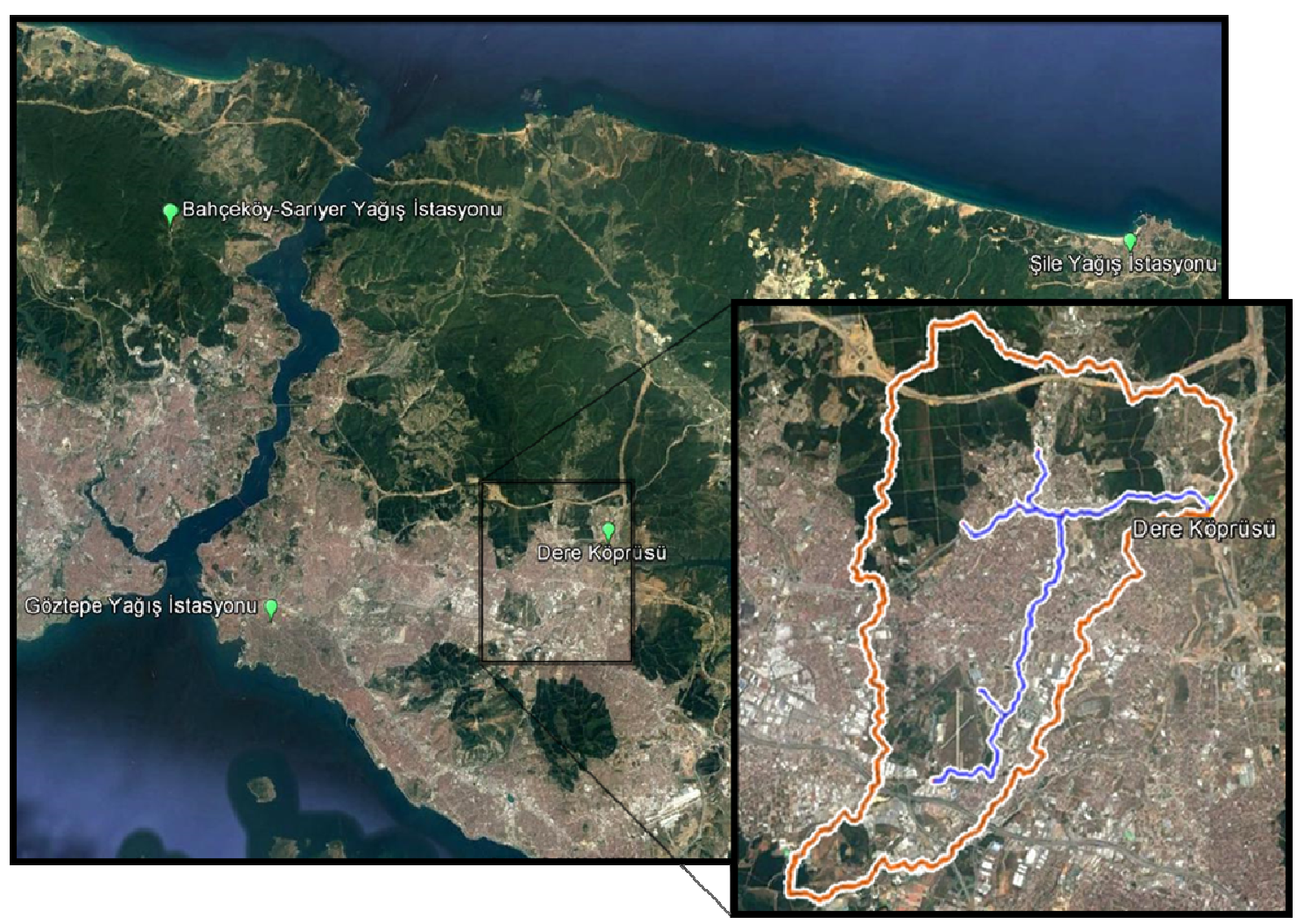

Şekil 4. KMO anahtar planı ve DK02'nin konumu. 
Tablo 2. Yağış istasyonu bilgileri.

\begin{tabular}{cccc}
\hline \hline MGM istasyon numarası & İstasyon adı & Enlem (K) & Boylam (D) \\
\hline 17619 & Bahçeköy-Sarıyer & $41.174^{\circ}$ & $28.990^{\circ}$ \\
17062 & Göztepe & $40.988^{\circ}$ & $29.056^{\circ}$ \\
17610 & Şile & $41.128^{\circ}$ & $29.380^{\circ}$ \\
\hline
\end{tabular}

Eğer bir bölgede birden çok yağış istasyonu varsa ilgili havzanın yağışını temsil etmesi için bir takım yöntemler mevcuttur. Bunlar aritmetik ortalama, Thiessen (ağırlıklı ortalama veya üçgenleme) ve eş yağış eğrisi yöntemleridir. Aritmetik ortalama yöntemi için tüm yağış istasyonlarının havza içinde bulunması icab eder fakat burada hiçbir ölçüm noktası havza dahilinde değildir. Eş yağış eğrileri için de çok sayıda istasyonun bulunması durumunda uygulanmaması önerilmektedir. Üçgenleme yöntemi ise her hâlükârda kullanıma müsaittir ve en yaygın kullanıma sahiptir. Dolayısıyla, Thiessen yöntemi burada da kullanılacak olsa herhangi hesaba gerek duyulmaksızın sadece Şekil 4'e göre çıplak gözle bile bakarak karar verilebilmektedir, çünkü Göztepe yağış istasyonu diğerlerine nazaran havzaya çok daha yakındır ve havzaya düşecek yağışı doğrudan temsil edebilmektedir. Çıkış noktası DK02 (Alemdağ, Ümraniye) olan havzanın alanı $40.2 \mathrm{~km}^{2}$ 'dir ve genel olarak Çekmeköy ve Ümraniye sınırları içinde yayılmaktadır. Ataşehir ve Maltepe'de de bir miktar kısımları bulunan havzanın merkezi yaklaşık $41.014^{\circ} \mathrm{K}$ ve $29.227^{\circ} \mathrm{D}$ kordinatlarına sahiptir. Tüm meteorolojik, hidrolojik ve hidrolik hesap ve tasarımlar Göztepe yağış istasyonu ölçümlerine dayalı olarak DK02 ve havzası için gerçekleştirilecektir.

İstanbul'un 33 m rakımlı Göztepe yağış istasyonunda yapılmış ölçümler 1942-2007 arasında 66 yılın en yüksek yağışları olarak seçilmiştir. Dolayısıyla toplam 66 tane fırtınalı yağışa göre analizler, tahminler ve hesaplar yapılarak sonuçlar ortaya koyulacaktır. İstasyondan temin edilen veriler her yılın 5, 10, 15, 30, 60, 120, 180, 240, 300, 360, 480, 720, 1080 ve 1440 dakikalık toplam yağış ölçümleridir. Debi hesabı için bu verilerin sadece 30 ve 60 dakikalık ölçümleri kullanılacaktır.

Uygulama üç aşamalı olarak gerçekleştirilecektir. Birinci adımda eğilim analizi Şen yöntemi yoluyla elde edilirken ikinci aşamada ihtimal hesapları yapılacaktır. Son kısma geçildiğinde ilgili yağış değerine göre havzada toplanacak pik debi ve DK02'nin debi kapasitesi hesaplanacaktır.

MGM'den alınan 2 adet (30 ve $60 \mathrm{dk}$ ) zaman serisinin her biri zamansal olarak 33'erli iki yarım parçaya ayrılmıştır. 1942-1974 arasında ölçülen veriler "birinci yarım”, 19752007 arasında ölçülen veriler ise "ikinci yarım" olarak adlandırılmıştır. Her bir yarımdaki değerler büyükten küçüğe sıralandıktan sonra eğilim çözümlemesine geçilmiştir. Sonuçta, Şekil 5 üzerinde sırasıyla 30 ve 60 dakikalık değerlerin trend analizi sunulmuştur. Bu şekilde yatay eksenler zaman serisinin birinci yarımını düşey eksenler ise ikinci yarımını temsil etmektedir. 


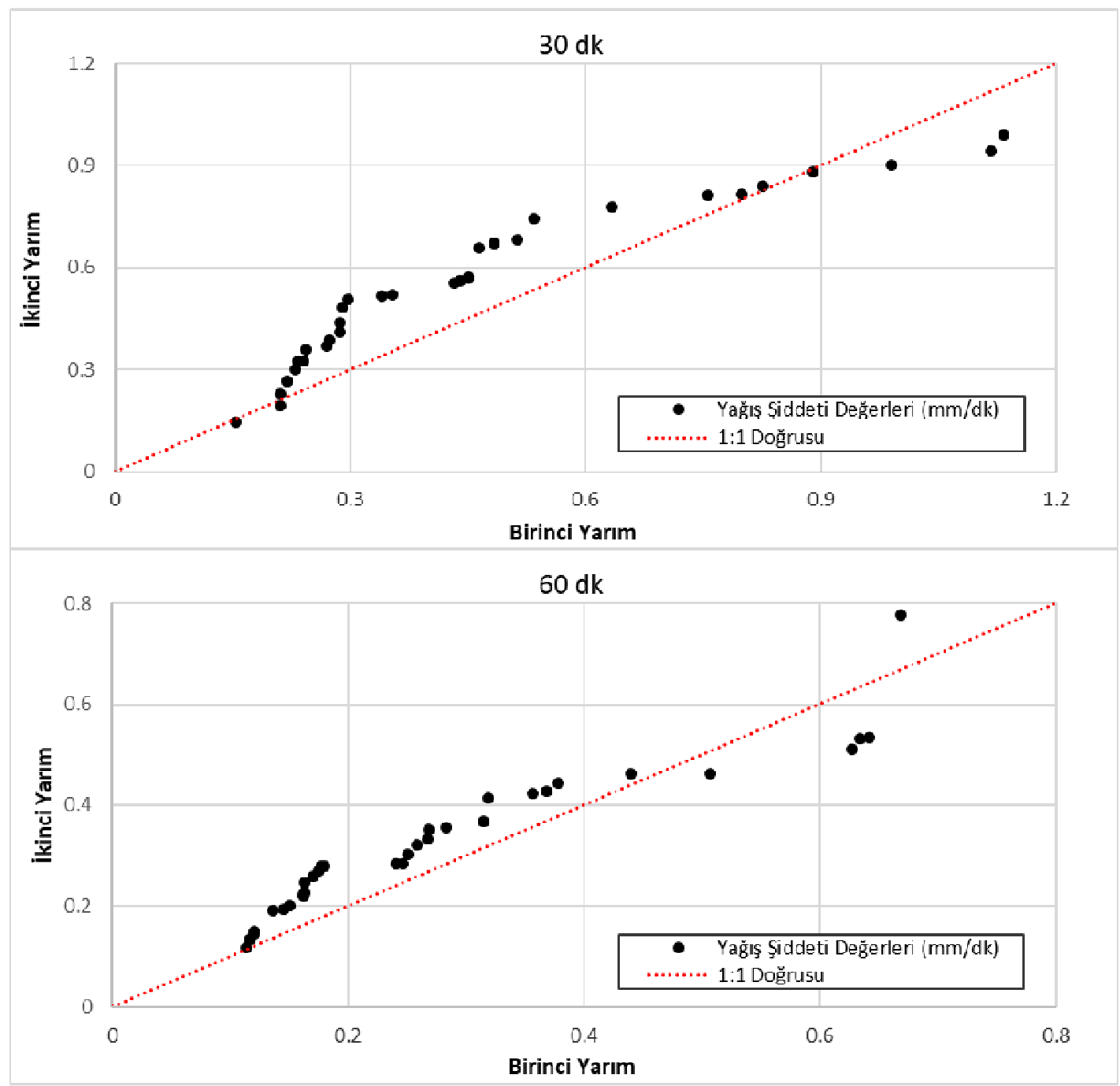

Şekil 5.30 ve $60 \mathrm{dk}$ yağıș şiddeti değerlerinin trend analizi.

Burada, 30 ve 60 dakika ölçümlerinin eğilimi neredeyse birbiriyle örtüşmüştür. Genel olarak, artan eğilim, uç değerlerde azalana dönmüştür. Özellikle uç değerlerde bir artış olsaydı, o zaman olasılık hesaplarında bir güvenlik katsayısı belirlenecekti veya Güçlü vd. [21]'nin uygulamasındaki gibi her iki yarım zaman serisi için ayrı ayrı hesaba başvurulacaktı. Sonuçta, ihtimal hesapların ortaya çıkarılması için zaman serilerinin tümü dikkate alınarak değerler üretilecektir. Ek olarak, Mann-Kendall sınaması zaman dizilerinde azalan trendin varlığına kuvvetli bir şekilde işaret etmiştir. Nitekim $\alpha$ anlamlılık seviyesi $\alpha=5 \% \quad(\mathrm{Z} \geq \mathrm{Z} \alpha / 2=| \pm 1.96|)$ düzeyinin üzerinde ve $\alpha=2 \%$ $(\mathrm{Z} \geq \mathrm{Z} \alpha / 2=| \pm 2.33|$ ) düzeyinin altında kalmıştır (Tablo 3). Bu sonuçlara göre zaman dizilerini tümden alarak hareket etmek güvenli tarafta kalmamıza imkân tanıyacaktır.

Tablo 3. Mann-Kendall trend sınaması sonuçları.

\begin{tabular}{cccccccc}
\hline \hline Süre & En Küçük & En Büyük & Ortalama & St. Sapma & S & Z & Eğilim \\
\hline $30 \mathrm{dk}$ & 0.1470 & 1.1330 & 0.5042 & 0.2596 & -414 & -2.2856 & Var (-) \\
$60 \mathrm{dk}$ & 0.1130 & 0.7770 & 0.3037 & 0.1558 & -417 & -2.3022 & Var (-) \\
\hline
\end{tabular}


$30 \mathrm{dk}$ ve $60 \mathrm{dk}$ süreli yağışlar için olasılık hesapları için 2 ve 3 parametreli 11 farklı dağılım dikkate alınarak adımlar atılmıştır. Log-Pearson-3, Weibull(3P), Weibull(2P), Gamma(3P), Gamma(2P), Lognormal(3P), Lognormal(2P), Gumbel, Normal, Üstel ve Genelleştirilmiş Ekstrem Değer dağılımları Kolmogorov Simirnov, Anderson Darling ve Ki-Kare sınamalarına göre birbiriyle kıyaslanmıștır. Tablo 4'te sınama neticelerine göre en uygun dağılım 1 en kötü dağılım 11 ile ifade edilmiştir. Bu şekilde yapılan sınıflandırmadan sonra en düşük toplam değere sahip dağılım olasılık hesabı için tercih edilmiştir. Weibull(3P) için toplam değer 20 bulunurken diğer 3 parametreli değerler için de 25 ve 25 'ten küçük değerler elde edilmiştir. Netice itibariyle Weibull(3P) ODF seçilerek yağış tahmini yapılmıştır.

Tablo 4. Dağglımların Kolmogorov Simirnov, Anderson Darling ve Ki-Kare testlerine göre siralamaları.

\begin{tabular}{clcccc}
\hline \hline Süre & Distribution & $\begin{array}{c}\text { Kolmogorov } \\
\text { Smirnov }\end{array}$ & $\begin{array}{c}\text { Anderson } \\
\text { Darling }\end{array}$ & Ki-Kare & Toplam \\
\hline Weibull (3P) & 1 & 1 & 6 & 8 \\
Gamma (3P) & 2 & 2 & 1 & 5 \\
Lognormal (3P) & 3 & 4 & 5 & 12 \\
Log-Pearson 3 & 4 & 3 & 3 & 10 \\
Lognormal (2P) & 5 & 5 & 4 & 14 \\
$30 \mathrm{dk}$ Gen. Ekstrem Değer & 6 & 7 & 8 & 21 \\
Gamma (2P) & 7 & 6 & 9 & 22 \\
Weibull (2P) & 8 & 9 & 10 & 27 \\
Gumbel & 9 & 8 & 2 & 19 \\
Normal & 10 & 10 & 11 & 31 \\
Üstel & 11 & 11 & 7 & 29 \\
\hline Weibull (3P) & 7 & 1 & 4 & 12 \\
Gamma (3P) & 9 & 8 & 2 & 19 \\
Lognormal (3P) & 4 & 6 & 1 & 11 \\
Log-Pearson 3 & 3 & 2 & 10 & 15 \\
Lognormal (2P) & 6 & 4 & 6 & 16 \\
Gen. Ekstrem Değer & 2 & 3 & 5 & 10 \\
Gamma (2P) & 1 & 5 & 3 & 9 \\
Weibull (2P) & 8 & 10 & 9 & 27 \\
Gumbel & 5 & 7 & 7 & 19 \\
Normal & 11 & 11 & 11 & 33 \\
Üstel & 10 & 9 & 8 & 27 \\
\hline
\end{tabular}

Bu çalışmada 100 yılda bir düşecek yağışa göre tasarım yapılacağından Şekil 6 üzerinde buna göre değer okuması yapılmıştır. Şekiller üzerinde f(x) ODF'nu, F(x) YDF'nu x ise yağış şiddeti değerlerini ifade etmektedir. Sıklık (Frekans) $=1 /$ (Tekerrür süresi) denklemi düşünüldüğünde 100 yıllık tekerrüre karşılık gelen sıklık 0.99 olacaktır. Şekil üzerinde ayrıca dağılım fonksiyonlarının parametre değerlerine de yer verilmiştir. Havzaya ait konsantrasyon süresi 45 dakika belirleneceğinden $1.3444 \mathrm{~mm} / \mathrm{dk}$ ve 0.8853 $\mathrm{mm} / \mathrm{dk}$ değerlerinin ortalamasına $(1.1149 \mathrm{~mm} / \mathrm{dk})$ göre tasarım debisi hesaplanacaktır. 

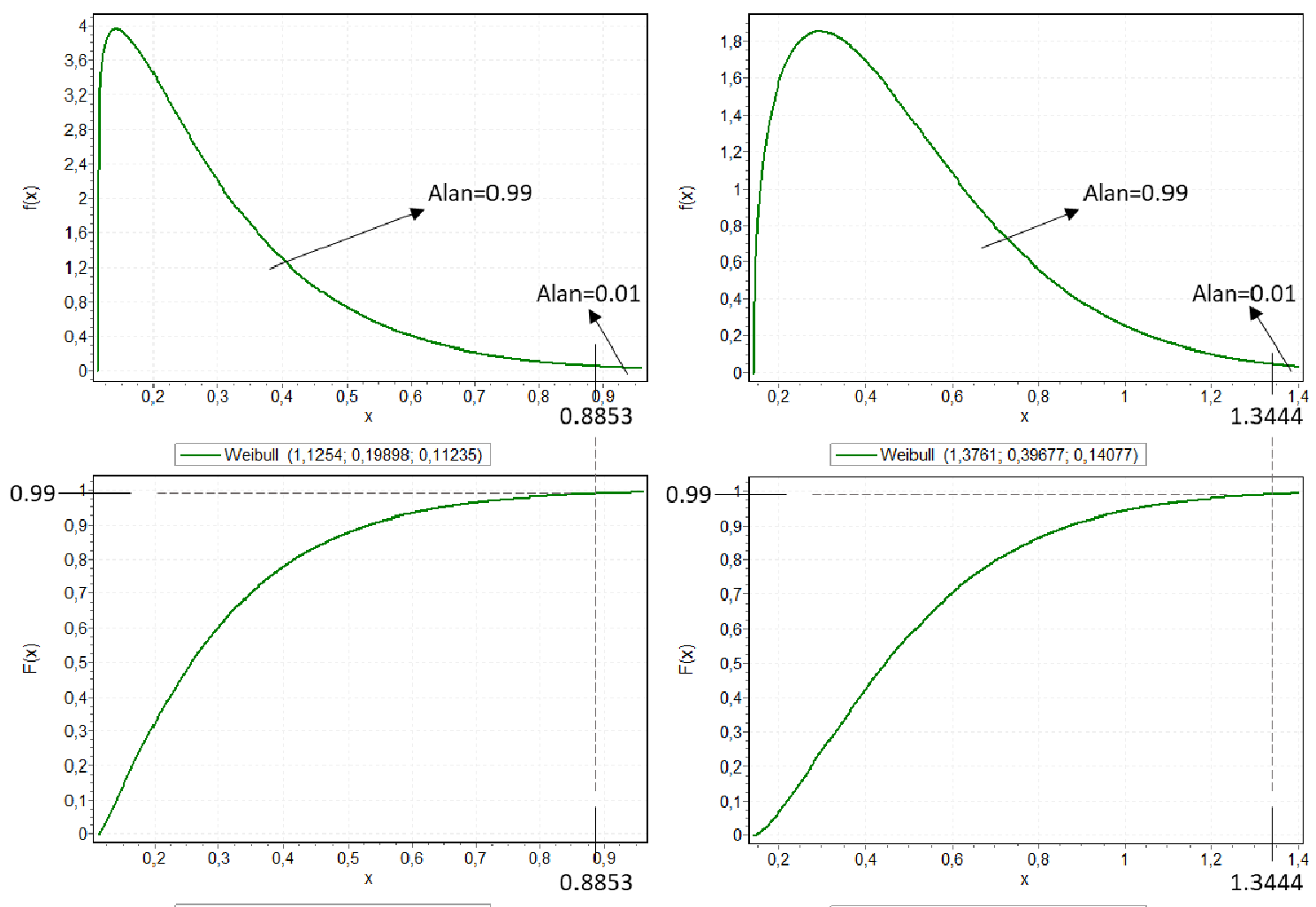

Şekil 6. 30 ve 60 dakika yağış şiddeti ölçümlerinin ODF ve YDF'ları.

DK02 çıkış noktasından 100 yılda bir geçmesi tahmin edilen debinin belirlenmesi gerekmektedir. İlgili havzanın bazı fiziksel özelliklerinin ortaya çıkarılması için sayısal yükselti model (SYM) verilerine ihtiyaç duyulmaktadır. İngilizce "Digital elevation model (DEM)" diye isimlendirilen 30 m çözünürlüğe sahip SYM verileri elde edildikten sonra ilgili havza sınırları kolaylıkla çizdirilebilmektedir (Şekil 7).

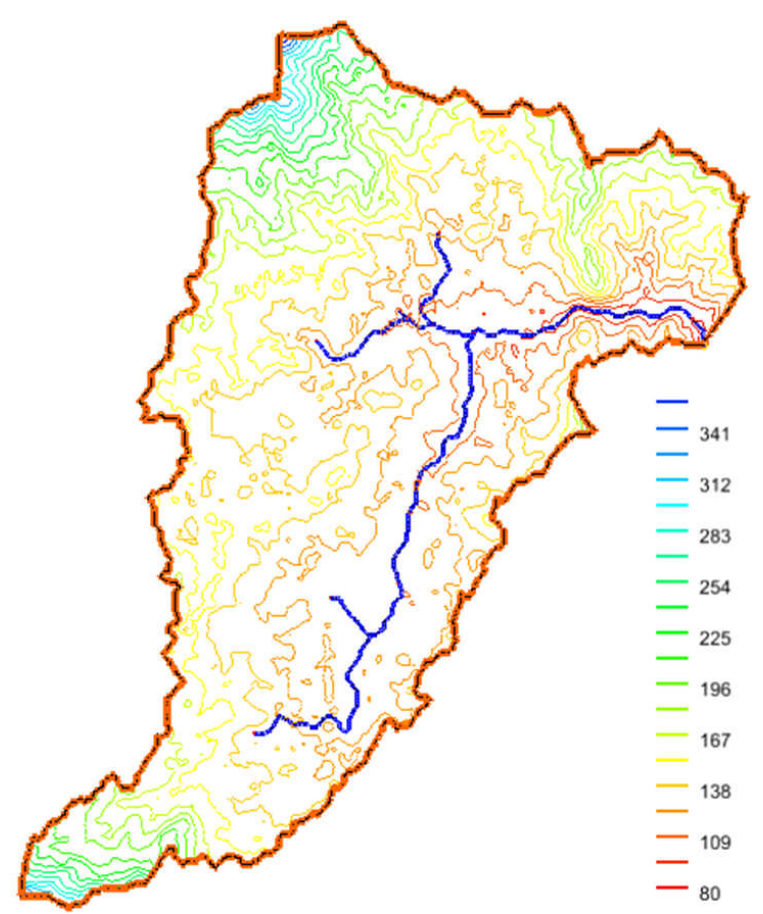

Şekil 7. DK02 havza sınırları (turuncu) ve asıl mecrası (mavi). 
Belirlenen havzanın asıl mecrası, doğrultusu, uzunluğu havzanın merkezinden çıkış noktasına olan uzaklığı gibi değerleri ortaya çıkarabilmektedir. Sonuç itibariyle, havzanın alanı, $\mathrm{A}=40.2 \mathrm{~km}^{2}$, asıl mecra uzunluğu, $\mathrm{L}=10.2 \mathrm{~km}$, havza merkezinin esas mecra üzerindeki iz düşüm noktasından çıkış noktasına kuş uçuşu uzunluğu ise $\mathrm{L}_{\mathrm{c}}=5.2$ $\mathrm{km}$ bulunmuştur. Denklem 4'te bulunan $\mathrm{C}_{\mathrm{t}}$ katsayısı çok küçük havza ve eğimli olması sebebiyle 0.3 değeri ile ifade edilmiştir. Buna göre, $\mathrm{t}_{\mathrm{p}} 0.75$ saat yani 45 dakika olarak hesaplanmıştır. Tasarım debisi için Denklem 5 ile hesap yapılmalıdır. Bunun için de $\mathrm{C}_{\mathrm{p}}$ katsayısı 1 ile ifade edilecektir. Bu durumda birim yükseklikteki $(10 \mathrm{~mm}) 45$ dakikalık yağışın ortaya çıkaracağı tepe debi yaklaşık $146 \mathrm{~m}^{3} / \mathrm{s}$ olacaktır. 100 yılda bir düşmesi öngörülen 45 dakikalık yağış değeri yaklaşık $50 \mathrm{~mm}(1.1149 \mathrm{~mm} / \mathrm{dkX} 45 \mathrm{dk})$ ve akış katsayısı da 0.6 belirlendiğine göre artık yağış $30.1 \mathrm{~mm}$ olacaktır. Basit bir orantı hesabı ile $10 \mathrm{~mm}$ yağış $146 \mathrm{~m}^{3} / \mathrm{s}$ ise $30.1 \mathrm{~mm}$ yağış yaklaşık $440 \mathrm{~m}^{3} / \mathrm{s}$ debiyi çıkış noktasında ortaya çıkaracaktır. Dolayısıyla, DK02 çıkış noktasında 100 yılda bir görülmesi beklenen debi $440 \mathrm{~m}^{3} / \mathrm{s}$ hesaplanmıştır. Burada dikkate alınan diğer yöntem DSİ yaklaşımının sonuçlarına göre maksimum debi yaklaşık $410 \mathrm{~m}^{3} / \mathrm{s}$ bulunduğundan güvenli tarafta kalmak adına Snyder yönteminin sonucu dikkate alınmıştır. Son olarak çıkış noktasının kanal en kesitine göre kanal kapasitesi belirlenecektir. Kanal en kesiti simetrik yamuk olmakla birlikte şev eğimleri 0.325 'tir ve Tablo 5'te hem kanalın kapasitesi hem de tasarım debisinin ortaya çıkması durumu ele alınmıştır ( $\mathrm{S}$, kanal eğimi; n, kanal sürtünme katsayısı; $\mathrm{B}_{\mathrm{t}}$, kanal enkesiti taban genişliği; $\mathrm{B}_{\mathrm{y}}$, kanal enkesiti yüzey genişliği; H, en kesit yüksekliği; A, enkesit alanı; U, 1slak çevre; R, hidrolik yarıçap; V, hız; Q, debi). Bu değişkenlerin değerleri aşağıdaki çizelgede gösterilmiştir.

Tablo 5. Kanal en kesiti için hidrolik hesabı.

\begin{tabular}{ccc}
\hline \hline Uzunluklar & Tam Dolu Akıș & Tasarım Debisi \\
\hline $\mathrm{S}$ & $1 / 180$ & $1 / 180$ \\
$\mathrm{n}$ & 0.017 & 0.017 \\
$\mathrm{~B}_{\mathrm{t}}(\mathrm{m})$ & 15 & 15 \\
$\mathrm{~B}_{\mathrm{y}}(\mathrm{m})$ & 17.6 & 17.21 \\
$\mathrm{H}(\mathrm{m})$ & 4 & 3.41 \\
$\mathrm{~A}\left(\mathrm{~m}^{2}\right)$ & 65.2 & 54.84 \\
$\mathrm{U}(\mathrm{m})$ & 23.41 & 22.16 \\
$\mathrm{R}(\mathrm{m})$ & 2.79 & 2.48 \\
$\mathrm{~V}(\mathrm{~m} / \mathrm{s})$ & 8.69 & 8.02 \\
$\mathrm{Q}\left(\mathrm{m}^{3} / \mathrm{s}\right)$ & 566.5 & 440 \\
\hline
\end{tabular}

Kanal enkesitinde hız hesabı için Denklem 9 (Manning denklemi) kullanılmıştır. Hesaplar sonucuna göre tasarım debisi ortaya çıktığında en kesitte yaklaşık $60 \mathrm{~cm}$ bir hava payı kalmaktadır.

\section{Sonuç}

$\mathrm{Bu}$ çalışmada İstanbul'un Asya kıtasında bulunan dere köprülerinden Ümraniye Alemdağ Dere Köprüsü (DK02) çalışma alanı seçilmiştir. Çıkış noktası DK02 (Alemdă̆, Ümraniye) olan havzanın alanı 40,2 $\mathrm{km}^{2}$ 'dir ve genelde, Çekmeköy ve Ümraniye sınırları içinde yayılmaktadır. Havzanın merkezi yaklaşı $41.014^{\circ} \mathrm{K}$ ve 
$29.227^{\circ} \mathrm{D}$ koordinatlarına sahiptir. Tüm meteorolojik, hidrolojik ve hidrolik hesap ve tasarımlar Göztepe Yağış İstasyonu ölçümlerine dayalı olarak DK02 ve havzası için gerçekleştirilmiştir. 1942-2007 yılları arasında İstanbul'un Göztepe yağış istasyonunda yapılmış ölçümlere göre analizler, tahminler ve hesaplar yapılarak sonuçlar ortaya koyulmuştur.

MGM'den alınan 2 adet zaman serisinin her biri 33'erli iki yarım parçaya ayrılmıştır. 1942-1974 arasında ölçülen veriler "birinci yarım", 1975-2007 arasında ölçülen veriler ise "ikinci yarım" olarak adlandırılmıştır. Sonuçta, sırasyıla 30 ve 60 dakikalık yağış şiddeti değerlerinin trend analizi sunulmuştur. Ölçümlerin eğilimi neredeyse birbiriyle örtüşmüştür. Genel olarak, artan trend, uç değerlerde azalana dönmüştür. Sonuçta, olasılık hesapların elde edilmesi için zaman serilerinin tümü dikkate alınarak değerler üretilmiştir.

Olasılık hesap yapmak adına 100 yıl tekerrür aralığına karşılık gelen değerler elde edilmiştir ve bunun için Kolmogorov Simirnov, Anderson Darling ve Ki-Kare sınama sonuçlarına göre Weibull(3P) ODF ve YDF kullanılmıştır. Havzaya ait konsantrasyon süresi 45 dakika belirlenirken $1.3444 \mathrm{~mm} / \mathrm{dk}$ ve $0.8853 \mathrm{~mm} / \mathrm{dk}$ değerlerinin ortalamasına $(1.1149 \mathrm{~mm} / \mathrm{dk})$ göre tasarım debisi hesaplanmıştır.

DK02 çıkış noktasından 100 yılda bir geçmesi tahmin edilen debinin belirlenmesi gerekmektedir. Havzanın alanı, $\mathrm{A}=40.2 \mathrm{~km}^{2}$, asıl mecra uzunluğu, $\mathrm{L}=10.2 \mathrm{~km}$, havzanın merkezinden çıkış noktasına kuş uçuşu uznluğu ise $\mathrm{L}_{\mathrm{c}}=5.2 \mathrm{~km}$ bulunmuştur. Birim yükseklikteki $(10 \mathrm{~mm}) 45$ dakikalık yağışın ortaya çıkaracağı tepe debi ise yaklaşık $146 \mathrm{~m}^{3} / \mathrm{s}$ hesaplanmıştır. 100 yılda bir düşmesi öngörülen 45 dakikalık yağıŞ değeri yaklaşık $50 \mathrm{~mm}(1.1149 \mathrm{~mm} / \mathrm{dkX} 45 \mathrm{dk})$ ve akış katsayısı da 0.6 belirlendiğine göre artık yağ 1 ş $30.1 \mathrm{~mm}$ 'dir. Basit bir orantı hesabı ile $10 \mathrm{~mm}$ yağış $146 \mathrm{~m}^{3} / \mathrm{s}$ ise 30.1 $\mathrm{mm}$ yağış yaklaşık $440 \mathrm{~m}^{3} / \mathrm{s}$ debiyi çıkış noktasında ortaya çıkaracaktır. DSİ yöntemine kıyasla Snyder yaklaşımının sonucu daha yüksek hesaplandığından $440 \mathrm{~m}^{3} / \mathrm{s}$ değerine göre boyutlandırma yapılmıştır. Son olarak çıkış noktasının kanal en kesitine göre kanal kapasitesi belirlenmiştir. En kesitte hız hesabı için Manning denklemi kullanılmıştır ve hesaplar sonucuna göre tasarım debisi ortaya çıtığında en kesitte yaklaşık $60 \mathrm{~cm}$ bir hava payı kalabilecektir, çünkü kanalın tam dolu akış durumunda $566.5 \mathrm{~m}^{3} / \mathrm{s}$ debi geçişi mümkün gözükmektedir.

Sonuç olarak, bu uygulama çalışması sayesinde doğruya yakın ve güvenilir bir şekilde dere köprüsünün tasarımına katkıda bulunulduğu düşünülmüştür. Özellikle trend analizlerinin de dikkate alınarak makalenin genişletilmesi bu çalışmayı bir adım daha ileri götüreceği ve diğer çalışmalara nazaran öne çıkaracağı kanaatine varılmıştır. Ancak burada Türkiye'nin çoğu bölgesinde olduğu gibi akış kayıtları bulunmadığı için yapay diğer bir ifadeyle amprik (deneysel) hidrolojik yöntemler dikkate alınmıştır. Bu yöntemlerin yağış-akış kayıtlarının eşgüdümlü hale getirilerek doğrulanması elzemdir. Böylece farklı bölgelere ait örnek bir takım havzalar elde edilecek ve buna göre gelecekte debi tahminine önemli katkıda bulunulacaktır. Aksi halde akıllarda güvenlik noktasında daima soru işaretleri kalacaktır veya boyutlandırmalar belli bir güvenlik katsayısına göre tasarlanıp inşa edilmelidir. Nitekim bu çalışmada hava payının yüksek tutulması bu güvenlik sorunu için bir önlem niteliğindedir. 
Kaynaklar

[1] Şen, Z., İklim değişikliği içerikli taşkın afet ve modern hesaplama yöntemleri, Su Vakfı, İstanbul, (2009).

[2] O'Connell, P.P.L., On the relation of the fresh-water floods of rivers to the areas and physical features of their basins; and on a method of classifying rivers and streams, with reference to the magnitude of their floods, Proceedings of the Institution of Civil Engineers, 27, 204-217, (1868).

[3] AREMWA (1911). Report of the Sub-Committee of Roadway Committee No. 1, Bulletin 131. Proceedings, 12(3), 481-528.

[4] Kuichling, E., The relation between the rainfall and the discharge of sewers in populous districts, Transactions of the American Society of Civil Engineers, 20(1), 1-56, (1889).

[5] Sherman, L.K., Streamflow from rainfall by the unit-graph method, Eng. News Record, 108, 501-505, (1932).

[6] Snyder, F.F., Synthetic unit graphs. Eos, Transactions American Geophysical Union, 19(1), 447-454, (1938).

[7] Chow, V.T., Hydrologic Determination of Waterway Areas for Design of Drainage Structures in Small Drainage Basins. Engineering Experiment Station Bulletin, No. 462, University of Illinois, (1962)..

[8] Eren, M.E., Boğluca (kayalı) deresinin taşkın riskinin irdelenmesi, Yüksek Lisans Tezi, Yıldız Teknik Üniversitesi Fen Bilimleri Enstitüsü, İstanbul, (2011).

[9] Günal, A. Y., Study on synthetic and unit hydrographs by using GIS and Artificial Intelligence Techniques, $\mathrm{PhD}$ Thesis, University of Gaziantep, Gaziantep, (2016).

[10] Doğu, A., Kırıkkale Çoruhözü deresinin taşkın pik debilerinin hesaplanması ve bir boyutlu modellenmesi, Yüksek Lisans Tezi, Kırıkkale Üniversitesi Fen Bilimleri Enstitüsü, Kırıkkale, (2016).

[11] İşler, S., Esin Oğuz, E. ve Durmuş O., Antalya Kemer ilçesi için sentetik yöntemlerle taşkın analizi, 4. Ulusal Taşkın Sempozyumu, Rize, (2016).

[12] Manning, R., On the flow of water in open channels and pipes, Transactions of theInstitution of Civil Engineers of Ireland, 20, 161-207, (1891).

[13] Ponce, V.M., Milestones of Hydrology, milestone contributions to hydrology and hydraulics, (2015). http://milestones.sdsu.edu/, (22.10.2017).

[14] Mann, H.B., Nonparametric tests against trend, Econometrica, 245-259, (1945).

[15] Kendall, M.G., Rank Correlation Methods, Charless Griffin, London, (1975).

[16] Sen, P.K., Estimates of the regression coefficient based on Kendall's tau, Journal of the American Statistical Association, 63, 1379-1389, (1968).

[17] Haan, C.T., Statistical methods in hydrology, The Iowa State University Press, Iowa, (1977).

[18] Şen, Z., Innovative trend analysis methodology, Journal of Hydrologic Engineering, 17(9), 1042-1046, (2012).

[19] Timbadiya, P.V., Mirajkar, A.B., Patel, P.L. ve Porey, P.D., Identification of trend and probability distribution for time series of annual peak flow in Tapi Basin, India, ISH Journal of Hydraulic Engineering, 19(1), 11-20, (2013).

[20] Şen, Z., Trend identification simulation and application, Journal of Hydrologic Engineering, 19(3), 635-642, (2014). 
[21] Mishra, A.K. ve Coulibaly, P., Variability in Canadian seasonal streamflow information and its implication for hydrometric network design, Journal of Hydrologic Engineering, 19(8), 05014003, (2014).

[22] Güçlü, Y.S., Comments on "Comparison of Mann-Kendall and innovative trend method for water quality parameters of the Kizilirmak River, Turkey (Kisi and Ay, 2014)" and "An innovative method for trend analysis of monthly pan evaporations (Kisi, 2015)”, Journal of Hydrology, 538, 878-882, (2016).

[23] Dabanlı, İ., Şen, Z., Yeleğen, M.Ö., Şişman, E., Selek, B. ve Güçlü, Y.S., Trend Assessment by the Innovative-Şen Method, Water Resources Management, 30(14), 5193-5203, (2016).

[24] Güçlü, Y.S., Şişman, E. ve Yeleğen, M.Ö., Climate change and frequencyintensity-duration (FID) curves for Florya station, Istanbul, Journal of Flood Risk Management, 11(S1), S403-S418, (2018).

[25] Kolmogorov, A., Sulla determinazione empirica di una lgge di distribuzione. Inst. Ital. Attuari, Giorn., 4, 83-91, (1933).

[26] Smirnov, N. V., On the estimation of the discrepancy between empirical curves of distribution for two independent samples, Bull. Math. Univ. Moscou, 2(2), 314, (1939).

[27] Anderson, T.W. ve Darling, D.A., Asymptotic theory of certain "goodness of fit" criteria based on stochastic processes, The annals of mathematical statistics, 193-212, (1952).

[28] Anderson, T.W. ve Darling, D.A., A test of goodness of fit, Journal of the American statistical association, 49(268), 765-769, (1954).

[29] Pearson, K., On the criterion that a given system of deviations from the probable in the case of a correlated system of variables is such that it can be reasonably supposed to have arisen from random sampling, Philosophical Magazine and Journal of Science, 50(302), 157-175, (1900).

[30] ASCE Design and Construction of Sanitary and Storm Sewers No. 37, Manual of Engineering Practice, (1960). 